\section{Influence of Dietary Levels of Protein and Sulfur Amino Acids on Metabolism of Glutathione and Related Amino Acids in Mice}

\author{
Tatsumi Adachi, ${ }^{*, a}$ Akira Yasutake, ${ }^{a}$ and \\ Kimiko Hirayama ${ }^{b}$
}

${ }^{a}$ Biochemistry Section, Department of Basic Medical Sciences, National Institute for Minamata Disease, Hama 4058-18, Minamata, Kumamoto 867-0008, Japan and ' Kumamoto University College of Medical Science, 4-24-1 Kuhonji, Kumamoto 862-0976, Japan

(Received April 30, 2002; Accepted July 8, 2002)

We investigated the metabolism of glutathione (GSH) and sulfur amino acids in various tissues of C57BL male mice fed on a $24.8 \%$ protein diet (normal protein diet, NPD), a $7.5 \%$ protein diet (low protein diet, LPD), and an amino acid supplemented diet (ASD), which contained $\mathbf{7 . 5 \%}$ protein and the same levels of sulfur amino acids as NPD. Although the hepatic total GSH (TGSH) concentration was lower in LPD-fed mice than in NPD-fed mice, that in ASD-fed mice recovered to the level in NPD-fed mice. TGSH concentrations in the brain and plasma were highest in ASD-fed mice, whereas those in the kidney and blood were similar in the three dietary groups. Concentrations of L-methionine and L-cystathionine, an intermediate in the metabolism from L-methionine to Lcysteine, in the brain, kidney and plasma were highest in ASD-fed mice, whereas hepatic concentrations were similar. Brain uptake of ${ }^{14} \mathrm{C}$-L-methionine for $60 \mathrm{~min}$ was higher in LPD-fed mice than in NPD-fed mice, and was further enhanced in ASD-fed mice. Accordingly, this would account for the highest brain concentrations of sulfur amino acids in ASD-fed mice. Thus, the concentrations of TGSH and sulfur amino acids were markedly higher in various tissues in ASD-fed mice than in not only LPD- but also NPD-fed mice. These results suggest that the metabolism of GSH and sulfur amino acids would drastically change by a supplement of sulfur amino acids with a lowered protein diet, at least partly because of their excessive levels compared with the other amino acids.

\footnotetext{
*To whom correspondence should be addressed: Biochemistry Section, Department of Basic Medical Sciences, National Institute for Minamata Disease, Hama 4058-18, Minamata, Kumamoto 867-0008, Japan. Tel.: +81-966-63-3111; Fax: +81966-61-1145; E-mail: taadachi@nimd.go.jp
}

Key words — dietary protein, sulfur amino acid, glutathione, L-methionine, L-cystathionine

\section{INTRODUCTION}

It has been well demonstrated that dietary levels of protein and sulfur amino acids affect the glutathione (GSH) metabolism. ${ }^{1-6)}$ For example, the hepatic GSH level is decreased by a deficiency of dietary protein and recovers by a supplement of Lmethionine or L-cysteine. ${ }^{6}$ )

The metabolism of thiol compounds such as GSH is closely related to the fate of methylmercury $(\mathrm{MeHg}){ }^{7,8)}$ which has a high affinity for the thiol group. ${ }^{9,10)}$ Accordingly, we have investigated the influence of dietary levels of protein and sulfur amino acids on the fate and toxicity of $\mathrm{MeHg}$ using mice fed a $24.8 \%$ protein diet (normal protein diet, NPD), a $7.5 \%$ protein diet (low protein diet, LPD) or an amino acid supplemented diet (ASD), which contains $7.5 \%$ protein and the same levels of sulfur amino acids as NPD. ${ }^{11-15)}$ Our experiments revealed that the distribution and excretion of $\mathrm{Hg}$ in ASD-fed mice was markedly different from those in NPD- or LPD-fed mice. ${ }^{12,13)}$ In addition, the concentrations of plasma low molecular weight thiol compounds such as L-cysteine and GSH were higher in ASDfed mice than in the other groups. ${ }^{12)}$ Therefore, we suggested that the marked alterations in the fate of MeHg observed in ASD-fed mice might be caused by a change in the metabolism of sulfur amino acids induced by their excessive levels compared with the other amino acids. However, the tissue levels of low molecular weight thiol compounds, most of which is GSH, remain unclear.

In the present study, further experiments were carried out on the tissue levels of GSH and sulfur amino acids in mice fed NPD, LPD or ASD to clarify the metabolism of excess sulfur amino acids in several tissues. Marked increases in these compounds were observed in various tissues in ASD-fed mice compared with NPD- or LPD-fed mice, especially in the brain.

\section{MATERIALS AND METHODS}

Animals — C57BL/6N male mice (aged 7 weeks) were obtained from CLEA Japan Co. (Osaka, Japan), maintained at $23 \pm 2{ }^{\circ} \mathrm{C}$ and $50-60 \%$ relative 
humidity, and exposed to a 12-hr light cycle from 7:00 a.m. The animals were housed individually and fed NPD, LPD, or ASD for $5 \mathrm{~d}$ before the experiment. The compositions of the powder diets were reported previously. ${ }^{11,12)}$ NPD and LPD contain 29.0 and $8.8 \%$ milk casein (24.8 and $7.5 \%$ protein), respectively, and ASD contains $8.8 \%$ milk casein (7.5\% protein), $1.1 \%$ L-methionine and $0.03 \% \mathrm{~L}$ cystine. All experimental procedures were approved by the Ethics Committee of the National Institute for Minamata Disease (NIMD).

Total GSH Assay — Under ether anesthesia, blood was collected from the inferior caval vein using a heparinized glass pipette, and an aliquot was centrifuged at $8000 \times g$ for $3 \mathrm{~min}$ to separate plasma. Then, the kidney, liver and brain were excised. These tissues were immediately deproteinized using 5\% perchloric acid containing $1 \mathrm{mM}$ ethylenediamine$\mathrm{N}, \mathrm{N}, \mathrm{N}^{\prime}, \mathrm{N}^{\prime}$-tetraacetic acid (EDTA). Total GSH (TGSH) in the supernatant was determined by the method of Tietze. ${ }^{16)}$

Amino Acid Analysis —_ Tissues of another group of mice were obtained as described above, and immediately deproteinized using $2 \%$ sulfosalicylic acid. Amino acid concentration was determined using a Hitachi Amino Acid Analyzer Model 835 after filtration with a $0.45 \mu \mathrm{m}$ filter (Millipore Co., Bedford, MA, U.S.A.).

Brain Uptake of ${ }^{14} \mathrm{C}$-L-methionine - Mice were intravenously injected with $\mathrm{L}$-[methyl- $\left.{ }^{14} \mathrm{C}\right]$ methionine $(1.85 \mathrm{MBq} / \mathrm{kg}$, DuPont/NEN Research Products, Boston, MA, U.S.A.) under pentobarbital anesthesia. Sixty min after the injection, each mouse was perfused with saline via the heart to remove the blood from the brain, which was then excised. After each brain was dissolved in SOLUENE $^{\circledR}-350$ (Packard Instrument Company, Inc., Meriden, CT, U.S.A.), liquid scintillator (HIONIC-FLUOR ${ }^{\mathrm{TM}}$, Packard Instrument Company, Inc.) was added and then mixed. Radioactivity in the brain was measured using an Aloka Liquid Scintillation System LSC3500 .

Statistical Analysis — Significant differences between individual means were determined by oneway analysis of variance (ANOVA) followed by Duncan's new multiple range test. Differences were considered significant at $p<0.05$.

\section{RESULTS AND DISCUSSION}

We previously reported that plasma low molecu- lar weight thiol compounds such as GSH were much higher in ASD-fed mice than in the other groups. ${ }^{12)}$ First, we determined the tissue concentrations of $\mathrm{GSH}$, which is the major non-protein thiol in tissues, in mice fed NPD, LPD or ASD for 5 days (Table 1). As demonstrated previously, ${ }^{11)}$ the TGSH concentration in liver was lower in LPD-fed mice than in NPD-fed mice, whereas those in brain, kidney, blood and plasma were similar in the two dietary groups. The TGSH concentration in the liver in ASD-fed mice was higher than in LPD-fed mice, and was the same as in NPD-fed mice. TGSH concentrations in the brain and plasma were higher in ASD-fed mice than in LPD- or NPD-fed mice, whereas no difference was observed in those in the kidney and blood.

Since L-cysteine, a constituent amino acid of $\mathrm{GSH}$, is converted from L-methionine in animal tissues, ${ }^{17)}$ we examined tissue L-methionine concentrations in NPD-, LPD- and ASD-fed mice (Table 2). There were no significant differences in the concentrations of L-methionine in any tissues between NPD- and LPD-fed mice. However, those in the brain, kidney and plasma in ASD-fed mice were 23 times higher than in the other dietary groups.

In animal tissues, L-methionine forms L-homocysteine through S-adenosyl L-methionine and S-adenosyl L-homocysteine. ${ }^{17)}$ When L-methionine is low, L-homocysteine is remethylated to L-methionine. ${ }^{17)}$ In contrast, if a remethylation is not needed, it converts to L-cystathionine with L-serine by cystathionine- $\beta$-synthetase, and then L-cystathionine is cleaved to L-cysteine and $\alpha$-oxo-butyrate by $\gamma$-cystathionase. ${ }^{17)}$ In this way, tissue levels of L-methionine, an essential amino acid, are controlled. These regulations would, at least partly, account for the lack of difference in tissue L-methionine concentrations between LPD- and NPD-fed mice. Surprisingly, the brain concentration of L-cystathionine in ASD-fed mice was more than 700 times higher than in NPD- and LPD-fed mice, whereas the renal concentration was only 5 times higher in ASD-fed mice, and the hepatic concentration was similar in the three groups (Table 2). In addition, Lcystathionine in plasma was detected in ASD-fed mice alone (Table 2). The activities in both cystathionine- $\beta$-synthetase and $\gamma$-cystathionase are much lower in the brain than in the liver and kidney in mice. ${ }^{18)}$ However, $\gamma$-cystathionase activity is much lower than cystathionine- $\beta$-synthetase activity in the brain, but only slightly lower in the kidney, whereas those activities are similar in the liver. ${ }^{18)}$ Accordingly, 
Table 1. Influence of Dietary Levels of Protein and Sulfur Amino Acids on Tissue TGSH Concentrations in Mice

\begin{tabular}{|c|c|c|c|c|c|}
\hline \multirow[t]{3}{*}{ Tissue } & & \multicolumn{3}{|c|}{ TGSH } & \multirow[t]{3}{*}{ ANOVA } \\
\hline & & \multicolumn{3}{|c|}{ Diet } & \\
\hline & & NPD & LPD & ASD & \\
\hline Brain & $(\mu \mathrm{mol} / \mathrm{g})$ & $1.91 \pm 0.06$ & $1.79 \pm 0.07$ & $2.15 \pm 0.16^{* * \#}$ & $p<0.01$ \\
\hline Liver & $(\mu \mathrm{mol} / \mathrm{g})$ & $10.15 \pm 0.83$ & $5.30 \pm 1.10^{* *}$ & $10.06 \pm 0.78^{\#}$ & $p<0.01$ \\
\hline Kidney & $(\mu \mathrm{mol} / \mathrm{g})$ & $4.67 \pm 0.12$ & $5.13 \pm 0.32$ & $4.92 \pm 0.20$ & NS \\
\hline Blood & $(\mu \mathrm{M})$ & $0.82 \pm 0.06$ & $0.73 \pm 0.06$ & $0.80 \pm 0.05$ & NS \\
\hline Plasma & $(\mathrm{nM})$ & $27.93 \pm 3.16$ & $24.11 \pm 3.47$ & $34.76 \pm 3.39 * \#$ & $p<0.01$ \\
\hline
\end{tabular}

The values represent the mean \pm S.D. obtained from 3 to 6 mice. NS, not significant. Significantly different from NPD-fed mice, ${ }^{*} p<0.05,{ }^{* *} p<0.01$. Significantly different from LPD-fed mice, ${ }^{\#} p<0.01$.

Table 2. Influence of Dietary Levels of Protein and Sulfur Amino Acids on Tissue Concentrations of L-Methionine and LCystathionine in Mice

\begin{tabular}{|c|c|c|c|c|c|}
\hline \multirow[t]{3}{*}{ Tissue } & & \multicolumn{3}{|c|}{ L-Methionine or L-Cystathionine } & \multirow[t]{3}{*}{ ANOVA } \\
\hline & & \multicolumn{3}{|c|}{ Diet } & \\
\hline & & NPD & LPD & ASD & \\
\hline & & & L-Methionine & & \\
\hline Brain & $(\mathrm{nmol} / \mathrm{g})$ & $52.72 \pm 6.32$ & $60.70 \pm 1.05$ & $185.59 \pm 44.07 * \#$ & $p<0.01$ \\
\hline Liver & $(\mathrm{nmol} / \mathrm{g})$ & $53.81 \pm 9.27$ & $43.85 \pm 3.31$ & $51.55 \pm \quad 7.58$ & NS \\
\hline Kidney & $(\mathrm{nmol} / \mathrm{g})$ & $73.08 \pm 27.58$ & $51.94 \pm 5.06$ & $134.77 \pm 36.23^{* \#}$ & $p<0.01$ \\
\hline Plasma & $(\mathrm{pM})$ & $67.40 \pm 15.94$ & $66.28 \pm 2.81$ & $172.00 \pm 61.79 * \#$ & $p<0.01$ \\
\hline & & & L-Cystathionin & & \\
\hline Brain & $(\mathrm{nmol} / \mathrm{g})$ & $19.47 \pm 4.06$ & $18.85 \pm 5.57$ & $1466.02 \pm 307.45^{* \#}$ & $p<0.01$ \\
\hline Liver & $(\mathrm{nmol} / \mathrm{g})$ & $68.00 \pm 24.06$ & $40.20 \pm 9.41$ & $98.80 \pm 38.44$ & NS \\
\hline Kidney & $(\mathrm{nmol} / \mathrm{g})$ & $10.25 \pm 1.49$ & $6.64 \pm 5.76$ & $53.52 \pm 19.64 * \#$ & $p<0.01$ \\
\hline Plasma & $(\mathrm{pM})$ & ND & ND & $10.15 \pm 2.35$ & \\
\hline
\end{tabular}

The values represent the mean \pm S.D. obtained from 3 to 4 mice. ND, not detected; NS, not significant. Significantly different from NPD-fed mice, ${ }^{*} p<0.01$. Significantly different from LPD-fed mice, ${ }^{\#} p<0.01$.

tissue differences in the balance of the enzyme activities for the synthesis and catabolism of L-cystathionine would be one reason for the marked accumulation of this amino acid in the brain compared with the liver and kidney in ASD-fed mice.

As described above, the concentrations of sulfur amino acids were markedly higher in ASD-fed mice than in the other groups, especially in the brain compared with the liver and kidney. When mice were intravenously injected with ${ }^{14} \mathrm{C}$-L-methionine, its uptake into the brain for 60 min was higher in LPDfed mice than in NPD-fed mice, and was further enhanced in ASD-fed mice (Fig. 1). Accordingly, this would account for the highest brain concentrations of sulfur amino acids in ASD-fed mice. However, diet-dependent alterations in the brain uptake rates of amino acids might vary, because we earlier reported that ${ }^{14} \mathrm{C}$-L-phenylalanine uptake into the brain was accelerated in LPD- and ASD-fed mice com- pared with that in NPD-fed mice. ${ }^{12)}$ In general, the reciprocal of the uptake rate of an amino acid into the cells is proportional to that of the extracellular concentration of the amino acid in double-reciprocal plot (Lineweaver-Burk plot). ${ }^{19)}$ When the plasma concentration of certain amino acid alone increases, its uptake rate into the tissues including brain would also increase before saturation. The plasma concentration of L-methionine was the highest in ASD-fed mice among the three groups (Table 2), whereas the concentration of L-phenylalanine was similar in the three dietary groups $(55.78 \pm 13.15,56.84 \pm 6.98$ and $50.57 \pm 9.41 \mathrm{pM}$ in NPD-, LPD- and ASD-fed mice, respectively; mean \pm S.D. obtained from 4 mice). Accordingly, this would, at least partly, cause the faster brain uptake rates of L-methionine in ASD-fed mice than LPD-fed mice, and the similar uptake rates of L-phenylalanine. Considering the similar plasma concentrations of L-phenylalanine, 


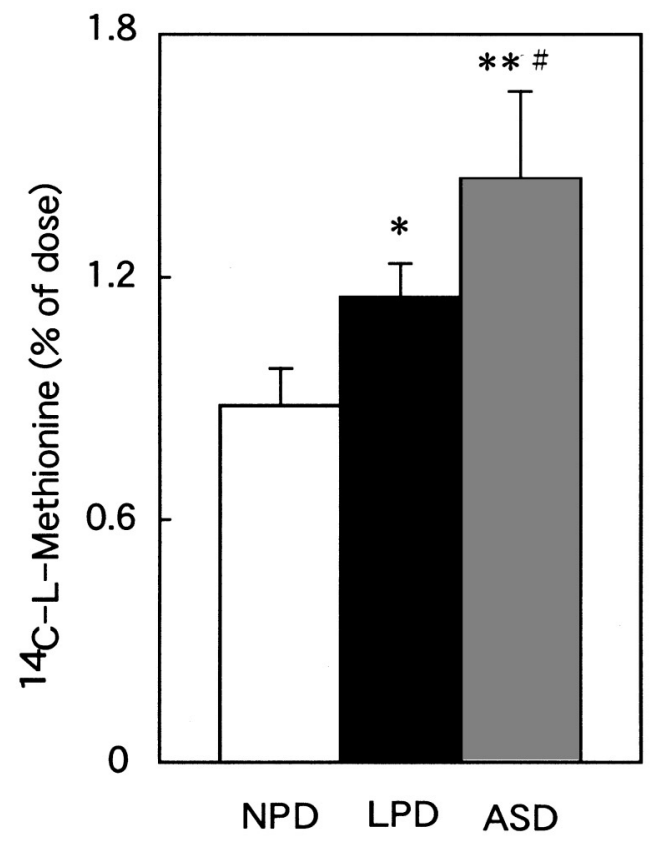

Fig. 1. Influence of Dietary Levels of Protein and Sulfur Amino Acids on Brain Uptake of ${ }^{14} \mathrm{C}$-L-Methionine in Mice

Mice were sacrificed $60 \mathrm{~min}$ after intravenous injection of ${ }^{14} \mathrm{C}$-Lmethionine $(1.85 \mathrm{MBq} / \mathrm{kg})$. The values represent the mean \pm S.D. obtained from 4 to 6 mice. ANOVA: NPD, LPD and ASD. $p<0.01$. Significantly different from NPD-fed mice, ${ }^{*} p<0.05,{ }^{*} p<0.01$. Significantly different from LPD-fed mice, $\# p<0.01$.

the results with regard to the brain uptake of L-phenylalanine suggest that the transport activity of neutral amino acids such as L-methionine and L-phenylalanine into the brain would be accelerated by dietary protein deficiency but not by a supplement of sulfur amino acids. This might also be the reason that there were no differences in tissue concentrations of L-methionine between NPD- and LPD-fed mice despite the insufficiency of sulfur amino acids caused by the lowered dietary protein level. However, further study would be necessary on the cellular or molecular mechanism of the alterations in the tissue uptake of neutral amino acids, because it is possible that diet-dependent alterations in the plasma concentrations of the other amino acids might affect the uptake of L-methionine and L-phenylalanine.

In the present study, the concentrations of both TGSH and sulfur amino acids in various tissues were found to be markedly higher in ASD-fed mice than in not only LPD- but also NPD-fed mice, especially in the brain. Our previous study revealed that part of the effects of L-methionine added to the diets on the fate of $\mathrm{MeHg}$ was dietary protein level-dependent, particularly in the brain. ${ }^{15)}$ The effects of the supplement were more drastic when L-methionine was supplemented to the lowered protein diet. These results convinced us that excess sulfur amino acids compared with the other amino acids would cause alterations in the metabolism of these amino acids including L-methionine and L-cystathionine in ASDfed mice. However, there might be tissue differences in the metabolism, since no marked differences were observed in the concentrations of L-methionine or L-cystathionine in the liver or in the TGSH concentration in the kidney among the three dietary groups. To elucidate the mechanism of such tissue differences, further study of the diet-dependent modulation of expression and/or activities of sulfur amino acid-metabolizing enzymes would be necessary.

\section{REFERENCES}

1) Seligson, F. H. and Rotruck, J. T. (1983) Tissue nonprotein sulfhydryl content and weight gain of rats as affected by dietary methionine level. J. Nutr., 113, 98-104.

2) Suberville, C., Higueret, P., Taruoura, D., Garcin, H. and Higueret, D. (1987) Relative contribution of cysteine and methionine to glutathione content and thyroid hormone levels in the rat. Br.J. Nutr., $\mathbf{5 8}$, 105-111.

3) Bauman, P. F., Smith, T. K. and Bray, T. M. (1988) Effect of dietary protein deficiency and L-2oxothiazolidine-4-carboxylate on the diurnal rhythm of hepatic glutathione in the rat. J. Nutr., 118, 10481054.

4) Garcin, H., Suberville, C., Higueret, P. and Higueret, D. (1989) Changes in glutathione status and 3,5,3'triiodothyronine action in livers of rats given cysteine-deficient diets. Br. J. Nutr., 61, 301-307.

5) Taniguchi, M., Hirayama, K., Yamaguchi, K., Tateishi, N. and Suzuki, M. (1989) Nutritional aspects of glutathione metabolism and function. In Glutathione: Chemical, Biochemical, and Medical Aspects, Part B (Dolphin D., Poulson, R. and Avramovic, O., Eds.), John Wiley and Sons, New York, pp. 645-727.

6) Ayala, A., Gordillo, E., Castaño, A., Lobato, M.-F. and Machado, A. (1991) Involvement of diminution of glutathione, produced by deficiency of methionine in the diet, in the elevation of malic enzyme level in rat liver. Biochim. Biophys. Acta, 1084, 48-52.

7) Hirayama, K., Yasutake, A. and Inoue, M. (1987) Effect of sex hormones on the fate of methylmercury and glutathione metabolism in mice. Biochem. Pharmacol., 36, 1919-1924.

8) Hirayama, K., Yasutake, A. and Adachi, T. (1991) 
Mechanism for renal handling of methylmercury. In Advances in Mercury Toxicology (Suzuki, T., Imura, N. and Clarkson, T. W., Eds.), Plenum Press, New York, pp. 121-134.

9) Simpson, R. B. (1961) Association constants of methylmercury with sulfhydryl and other bases. $J$. Am. Chem. Soc., 83, 4711-4717.

10) Bach, R. D. and Weibel, A. T. (1976) Nuclear magnetic resonance studies on anion-exchange reactions of alkylmercury mercaptides. J. Am. Chem. Soc., 98, 6241-6249.

11) Adachi, T., Yasutake, A. and Hirayama, K. (1992) Influence of dietary protein levels on the fate of methylmercury and glutathione metabolism in mice. Toxicology, 72, 17-26.

12) Adachi, T., Yasutake, A. and Hirayama, K. (1994) Influence of dietary levels of protein and sulfur amino acids on the fate of methylmercury in mice. Toxicology, 93, 225-234.

13) Adachi, T., Yasutake, A. and Hirayama, K. (1995) Influence of dietary levels of protein and sulfur amino acids on the subacute toxicity of methylmercury in mice. Jpn. J. Toxicol. Environ. Health, 41, 411-418.
14) Adachi, T., Yasutake, A., Eto, K. and Hirayama, K. (1996) Influence of dietary protein levels on the acute toxicity of methylmercury in mice. Toxicology, 112, 11-17.

15) Adachi, T. and Hirayama, K. (1998) Dietary protein levels cause different effects of methionine supplement on the fate of methylmercury in mice. Jpn. J. Toxicol. Environ. Health, 44, 226-232.

16) Tietze, F. (1969) Enzymic method for quantitative determination of nanogram amounts of total and oxidized glutathione: applications to mammalian blood and other tissues. Anal. Biochem., 27, 502522.

17) Bender, D. A. (1975) Amino Acid Metabolism, John Wiley and Sons, London, pp. 112-142.

18) Myojin, K., Hiroi, T., Ikeda, H. and Kodama, H. (1992) Sulfur amino acid levels and related enzyme activities in various brain regions (and other tissues) in normal mice and rolling mice Nagoya. Acta Med. Okayama, 46, 401-405.

19) Christensen, H. N. (1985) On the strategy of kinetic discrimination of amino acid transport systems. $J$. Membr. Biol., 84, 97-103. 